JOURNAL OF BACTERIOLOGY, /Sept. 1992, p. 5941-5952 $0021-9193 / 92 / 185941-12 \$ 02.00 / 0$

Vol. 174, No. 18

Copyright @ 1992, American Society for Microbiology

\title{
A Rhizobium meliloti Lipopolysaccharide Mutant Altered in Competitiveness for Nodulation of Alfalfa
}

\author{
A. LAGARES, ${ }^{1,2} \dagger^{*}$ G. CAETANO-ANOLLÉS, ${ }^{3}$ K. NIEHAUS, ${ }^{4}$ J. LORENZEN, ${ }^{4}$ \\ H. D. LJUNGGREN, ${ }^{2}$ A. PÜHLER, ${ }^{4}$ AND G. FAVELUKES ${ }^{1}$ \\ Cátedra de Química Biológica I, Facultad de Ciencias Exactas, Universidad Nacional de La Plata, 47 y 115 1900-La \\ Plata, Argentina ; Department of Microbiology, Swedish University of Agricultural Sciences, Uppsala, Sweden ${ }^{2}$; \\ Plant Molecular Genetics, Institute of Agriculture and Center for Legume Research, The University of \\ Tennessee, Knoxville, Tennessee 37901-107133; and Lehrstuhl für Genetik, Fakultät für Biologie, \\ Universität Bielefeld, Postfach 100131, D-4800-Bielefeld 1, Germany ${ }^{4}$
}

Received 16 April 1992/Accepted 21 July 1992

\begin{abstract}
A transposon Tn5-induced mutant of Rhizobium meliloti $R \mathbf{m} 2011$, designated Rm6963, showed a rough colony morphology on rich and minimal media and an altered lipopolysaccharide (LPS). Major difierences from the wild-type LPS were observed in (i) hexose and 2-keto-3-deoxyoctonate elution profiles of crude phenol extracts chromatographed in Sepharose CL-4B, (ii) silver-stained sodium dodecyl sulfate (SDS)-polyacrylamide gel electrophoresis patterns of crude and purified LPS fractions, and (iii) immunoreactivities otherwise present in purified LPS of the parental strain Rm2011. In addition, Rm6963 lost the ability to grow in Luria-Bertani medium containing the hydrophobic compounds sodium deoxycholate or SDS and showed a decrease in survival in TY medium supplemented with high calcium concentrations. The mutant also had altered symbiotic properties. Rm6963 formed nodules that fixed nitrogen but showed a delayed or even reduced ability to nodulate the primary root of alfalfa without showing changes in the position of nodule distribution profiles along the roots. Furthermore, 2 to 3 weeks after inoculation, plants nodulated by Rm6963 were smaller than control plants inoculated with wild-type bacteria in correlation with a transient decrease in nitrogen fixation. In most experiments, the plants recovered later by expressing a full nitrogen-fixing phenotype and developing an abnormally high number of small nodules in lateral roots after 1 month. Rm6963 was also deficient in the ability to compete for nodulation. In coinoculation experiments with equal bacterial numbers of both mutant and wild-type rhizobia, only the parent was recovered from the uppermost root nodules. A strain ratio of approximately 100 to 1 favoring the mutant was necessary to obtain an equal ratio (1:1) of nodule occupancy. These results show that alterations in Rm6963 which include LPS changes lead to an altered symbiotic phenotype during the association with alfalfa that affects the timing of nodule emergence, the progress of nitrogen fixation, and the strain competitiveness for nodulation.
\end{abstract}

Bacteria of the genera Rhizobium and Bradyrhizobium have the ability to infect roots of leguminous plants to form nitrogen-fixing nodules $(1,43)$. The resulting symbiosis, highly specific with respect to the involved partners, develops along an ordered multistage interaction, with participation of plant and rhizobial components and specific soluble signals $(26,33)$. Thus, a complex, developmentally regulated association takes place under the coordinated expression of several symbiotic genes in the plant and the bacteria $(44,49)$.

Several bacterial surface components have been investigated and proved to be necessary for a compatible interaction of the bacteria with the host plant. Glucans (31), exopolysaccharides $(5,20,21,42,45)$, and lipopolysaccharides (LPS) $(6,13,19,47)$ all appear to play a role during symbiotic interaction, especially during plant recognition and infection $(1,11)$.

The symbiotic role of LPS-and also exopolysaccharides-was at first investigated by analyzing their interactions with legume lectins or roots $(35,38,41)$. With these kinds of studies, appropriate amounts of purified LPS from different rhizobia were shown to trigger metabolic events in white clover affecting infection thread development (24). By

\footnotetext{
* Corresponding author. Electronic mail address: antonio@ biogene1.uni-bielefeld.de.

$\uparrow$ Present address: Lehrstuhl für Genetik, Fakultät für Biologie, Universität Bielefeld, Bielefeld, Germany.
}

a different approach, in an attempt to characterize the participation of LPS in symbiosis, changes in the composition of LPS were found among nodulating and nonnodulating strains of Rhizobium leguminosarum bv. trifolii $(16,50,51)$ and Rhizobium fredii (17) after the loss of whole plasmids. Various mutants with alterations in LPS were defective in the symbiotic association at different stages of development. Single-transposon Tn 5 mutations in $R$. leguminosarum bv. phaseoli $(19,46)$, bv. viciae $(25,47)$, and bv. trifolii $(6)$ and Bradyrhizobium japonicum (56) altered simultaneously both LPS structure and symbiosis. The kind of symbiotic alterations derived from these LPS changes varied with the bacteria examined. In $R$. leguminosarum bv. phaseoli and bv. viciae, rough variants were clearly defective in infection and nodule development $(46,47)$. It has been proposed that $R$. leguminosarum LPS could determine surface charge or hydrophobicity, both important for bacterial release from the infection threads (25). However, the expression of a heterologous $\mathrm{O}$ antigen in $R$. leguminosarum bv. trifolii can still support a normal symbiosis (6). Despite this apparently relaxed requirement for a symbiotically active LPS, changes in specific epitopes of the $\mathbf{O}$ antigen occur during the process of bacteroid differentiation $(32,54)$. In $R$. leguminosarum bv. phaseoli, similar changes also occur in free-living bacteria grown at low $\mathrm{pH}$ and were shown to be independent of the presence of Sym plasmid genes (58). Progress in understanding the chemistry of LPS is currently being made to 
TABLE 1. Microorganisms and plasmids

\begin{tabular}{|c|c|c|}
\hline $\begin{array}{l}\text { Strain, phage, } \\
\text { or plasmid }\end{array}$ & Relevant characteristic(s) & Source or reference \\
\hline \multicolumn{3}{|l|}{$\begin{array}{l}\text { Strains } \\
\quad R \text {. meliloti }\end{array}$} \\
\hline RmL5-30 & Wild type & G. Martínez, Dretz, Uruguay \\
\hline Rm1021 & Wild type & S. R. Long, United States \\
\hline Rm2011 & Wild type, $\mathrm{Sm}^{\mathrm{r}}$ & J. Dénarié, France \\
\hline Rm6963 & $\begin{array}{l}\text { Tn5 mutant derivative of } \mathrm{Rm} 2011, \mathrm{Nod}^{+} \mathrm{Fix}^{+}, \text {altered LPS, altered } \\
\text { in competitiveness for nodulation of alfalfa, } \mathrm{Sm}^{\mathrm{r}} \mathrm{Nm}^{\mathrm{r}}\end{array}$ & This work \\
\hline E. coli & & \\
\hline S17.1 & MM294, RP4-2-Tc::Mu-Km::Tn7 integrated in the chromosome, $\mathrm{Tp}^{\mathrm{r}}$ & 47 \\
\hline Phage & & \\
\hline $\begin{array}{r}\phi \mathrm{M} 12 \\
\text { Plasmid }\end{array}$ & Transducing phage & 29 \\
\hline $\begin{array}{l}\text { Plasmid } \\
\text { pSUP1021 }\end{array}$ & $\mathrm{Tn} 5$ derivative of pSUP102, $\mathrm{Amp}^{\mathrm{r}} \mathrm{Cm}^{\mathrm{r}} \mathrm{Tc}^{\mathrm{r}} \mathrm{Nm}^{\mathrm{r}}$ & 47 \\
\hline
\end{tabular}

account for this and other LPS structures that support epitopes of symbiotic relevance (for a review, see reference 14).

The participation of LPS in the association between Rhizobium meliloti and alfalfa is currently also under active investigation. Although an early role for LPS in plant recognition during bacterial adsorption to roots has been suggested elsewhere (41), other results have supported the hypothesis of participation of LPS later in symbiosis $(48,62$, 63). Interestingly, mutations in some exo loci causing ineffective nodulation were suppressed by $l p s Z$, a gene present in $\mathrm{Rm} 41$-derivative strains, restoring the production of nitrogen-fixing nodules (63). However, mutational alteration of $R$. meliloti LPS appears to have little or no effect in symbiosis. This theory could be upheld by the evidence that from a broad group of LPS mutants, none appeared to be deficient in the association with alfalfa (23). All of these mutants were able to fix nitrogen like the wild-type strain, and only some of them under a bacterial background carrying other surface mutations resulted in $\mathrm{Fix}^{-}$. It was suggested, however, that this phenotype was due to a cumulative effect of several independent mutations (23).

In the present paper, we characterize changes in the biochemistry and physiology of an $R$. meliloti LPS mutant that was able to fix atmospheric nitrogen but was clearly altered in symbiosis. We show that alterations in the mutant affected the timing of nitrogen fixation and the ability to compete for nodulation. The possible role of LPS during the association of the bacteria with alfalfa will be discussed.

(A preliminary summary of this work was presented at the 13th North American Symbiotic Nitrogen Fixation Conference, Banff, Alberta, Canada, 25 to 30 August 1991 [abstract P14p].)

\section{MATERIALS AND METHODS}

Plants, microorganisms, and plasmids. Alfalfa (Medicago sativa L. cv. Vernal) seeds were surface sterilized as previously described (8). Briefly, alfalfa seeds were pretreated with $97 \%$ ethanol for $1 \mathrm{~h}$ and then treated for 10 min with $0.2 \%$ (wt/vol) $\mathrm{HgCl}_{2}-0.5 \%$ (vol/vol) $\mathrm{HCl}$ and four washes with sterile water. The seeds were germinated on inverted water-agar petri dishes and used in plant nodulation experiments. Microorganisms and plasmids are described in Table 1.

Media and growth conditions. Bacterial strains were cultured in yeast extract-mannitol (YEM) medium (in grams per liter: yeast extract, 0.4 ; mannitol, $10 ; \mathrm{NaCl}, 0.1 ; \mathrm{MgSO}_{4}$.
$7 \mathrm{H}_{2} \mathrm{O}, 0.2 ; \mathrm{K}_{2} \mathrm{HPO}_{4}, 0.5$ [pH 7.0]) for nodulation assays and in defined glutamate-mannitol (GM) medium (in grams per liter: sodium glutamate, 1.1 ; mannitol, $10 ; \mathrm{K}_{2} \mathrm{HPO}_{4}, 0.23$; $\mathrm{MgSO}_{4} \cdot 7 \mathrm{H}_{2} \mathrm{O}, 0.1$; and $\mathrm{CaCl}_{2}, 0.005$; trace elements and vitamins [in micrograms per milliliter]: $\mathrm{H}_{3} \mathrm{BO}_{3}, 145 ; \mathrm{FeSO}_{4}$. $7 \mathrm{H}_{2} \mathrm{O}, 125 ; \mathrm{CoSO}_{4} \cdot 7 \mathrm{H}_{2} \mathrm{O}, 70 ; \mathrm{CuSO}_{4} \cdot 7 \mathrm{H}_{2} \mathrm{O}, 5 ; \mathrm{MnCl}_{2}$. $7 \mathrm{H}_{2} \mathrm{O}, 4 ; \mathrm{ZnSO}_{4} \cdot 7 \mathrm{H}_{2} \mathrm{O}, 108 ; \mathrm{Na}_{2} \mathrm{MoO}_{4}, 125$; nitrilotriacetate, 7,000; riboflavin, 20; nicotinic acid, 20; biotin, 20; $\mathrm{HCl}$-thiamine, 20; HCl-pyridoxin, 20; calcium pantothenate, 20; inositol, 120 [pH 7.0]) for LPS preparations. Bacteria in genetic manipulations were grown in tryptone-yeast extract (TY) medium (3) or Vincent minimal medium or modified Luria-Bertani (LB) medium (containing, in grams per liter: glucose, 1 ; tryptone, 10 ; yeast extract, 5 ; and $\mathrm{NaCl}, 5 \mathrm{pH}$ 6.80 to 6.85$])(60)$ as indicated. When appropriate, the media were supplemented with streptomycin $(400 \mu \mathrm{g} / \mathrm{ml})$ and/or neomycin $(120 \mu \mathrm{g} / \mathrm{ml})$.

General Tn5 mutagenesis. The Escherichia coli strain S17.1 carrying the tra gene region of RP4 integrated in the chromosome was used to transfer the suicide vector pSUP2021 carrying transposon Tn5 to strain Rm2011 (53). Neomycin-resistant $\left(\mathrm{Nm}^{\mathrm{r}}\right)$ transconjugants were isolated on TY medium containing the antibiotic.

Generalized transduction. Transduction of $\mathrm{Nm}^{\mathrm{r}}$ marker from Rm6963 to Rm2011 was done by using the transducing phage $\phi \mathrm{M} 12$ according to the protocol described by Finan et al. (29).

LPS preparations. Bacterial cultures of $\mathrm{Rm} 2011$ and Rm6963 were grown in liquid GM medium to late log phase (optical density at $500 \mathrm{~nm}\left[\mathrm{OD}_{500}\right]=0.5$ to 0.8 ) and centrifuged for $20 \mathrm{~min}$ at $10,000 \times \mathrm{g}$. LPS from harvested cells was extracted with a $45 \%$ phenol-water mixture as described elsewhere (61). The aqueous phases after two extractions were pooled and exhaustively dialyzed (membrane cutoff, 12 $\mathrm{kDa}$ ) against distilled water at $4^{\circ} \mathrm{C}$. This crude LPS solution was lyophilized and stored at $-20^{\circ} \mathrm{C}$.

LPS purification by chromatography on Sepharose CL-4B. Crude LPS extracts were resuspended in $100 \mathrm{mM}$ EDTAtriethylamine (pH 7.0) and the suspension was kept overnight at $4^{\circ} \mathrm{C}$ to enhance dissociation. LPS samples (6 to 12 $\mathrm{mg}$ as hexoses in 1 to $2 \mathrm{ml}$ ) were separated in a Sepharose CL-4B column $(2$ by $60 \mathrm{~cm}$ ) with $10 \mathrm{mM}$ EDTA-triethylamine running buffer ( $\mathrm{pH} \mathrm{7.0)}$ at $4^{\circ} \mathrm{C}(15)$.

Determination of hexoses and KDO. Crude LPS and subfractions obtained from the Sepharose CL-4B column were assayed for hexoses by the phenol-sulfuric method (27). The 
2-keto-3-deoxyoctonate (KDO) content was determined by the method described by Karkhanis et al. (37).

Colorimetric measurement of hydrophobicity. The spectral shift of the lipophilic probe merocyanin 540 (64) in the presence of hydrophobic compounds was used to estimate hydrophobicity. We observed a spectral shift to longer wavelengths when the cyanine reacted with solutions containing LPS. The coefficient $R\left[R=\left(\mathrm{OD}_{567} / \mathrm{OD}_{500}\right)_{\text {sample }}-\right.$ $\left.\left(O D_{567} / O D_{500}\right)_{\text {buffer }}\right]$ was linear with LPS concentrations in the range of 20 to $400 \mu \mathrm{g} / \mathrm{ml}$. A $900-\mu l$ volume of each sample was mixed with $100 \mu \mathrm{l}$ of $50 \mu \mathrm{g}$ of merocyanin per ml prepared immediately before use. After mixing, optical densities were measured and $R$ was calculated. This method was used to analyze fractions corresponding to the maximum of each peak eluted through the Sepharose CL-4B column.

SDS-polyacrylamide gel electrophoresis (PAGE). LPS preparations were solubilized in sample buffer (final concentrations: Tris- $\mathrm{HCl}, 0.0625 \mathrm{M}$; sodium dodecyl sulfate [SDS], $2 \%$ [wt/vol]; $\beta$-mercaptoethanol, $5 \%$ [vol/vol], bromophenol blue, $0.001 \%$ [wt/vol]; glycerol, $10 \%$ [vol/vol] $)$ and heated for 2 min at $100^{\circ} \mathrm{C}$. A $4 \%$ stacking gel and a $12 \%$ separation gel with the Laemmli (40) buffer systems were used. Gels were fixed and silver stained as described by Tsai and Frasch (59).

Sensitivity of $R$. meliloti to hydrophobic compounds. The ability of $R$. meliloti to grow in the presence of sodium deoxycholate (DOC) was tested by plating appropriate bacterial dilutions in LB solid medium containing from 0.05 to 2 $\mathrm{g}$ of DOC per liter. In each case, the $\mathrm{pH}$ was adjusted to 6.80 to 6.85 . Viability was expressed as the percentage ratio of colonies developed in the presence and absence of DOC. LB medium was also used to study the sensitivity of the mutant to SDS (0.1 g/liter).

Nodulation profiles in alfalfa primary-root and split-root experiments. Two-day-old seedlings were transferred to ethylene oxide-sterilized plastic growth pouches containing 10 ml of nitrogen-free Jensen mineral solution (34). Three days later, primary roots were inoculated by dripping $100 \mu$ l of bacterial suspension onto the root from the tip toward the base. The positions of the root tips and smallest emergent root hairs were marked on the plastic pouches immediately after inoculation with the aid of a dissecting microscope at a magnification of $\times 12$. The plants were cultured in a growth chamber at $80 \%$ relative humidity, at $26^{\circ} \mathrm{C}$ during the day and $24^{\circ} \mathrm{C}$ during the night, for a photoperiod of $16 \mathrm{~h}$, and at a photosynthetically active radiation rate of $250 \mathrm{mmol} \cdot \mathrm{s}^{-1}$. $\mathrm{m}^{-2}$. The number and relative location of individual nodules were determined with a computer-linked graphic tablet (4). Split-root experiments were carried out as previously described $(7,10)$.

Coinoculation experiments. Alfalfa plants grown in 250-ml pots filled with sand and nitrogen-free Jensen solution were inoculated 5 days after germination with late-log-phase cultures of Rm6963 and Rm2011. To prepare the inoculants, both strains were mixed in different proportions to obtain bacterial concentration ratios that ranged from approximately $10^{7}: 10^{7}$ to $10^{7}: 1$ bacteria $\cdot \mathrm{ml}^{-1}(\mathrm{Rm} 6963$ to $\mathrm{Rm} 2011)$. Pots containing 30 plants were inoculated with $3 \mathrm{ml}$ of the bacterial suspensions. In nodule occupancy studies, the uppermost root nodules were excised, surface sterilized in 20 vol of $\mathrm{H}_{2} \mathrm{O}_{2}(15 \mathrm{~min})$, and crushed in a 100- $\mu$ l Fåhraeus (28) mineral solution. The resulting suspensions were picked in solid medium with $1 \mathrm{~g}$ of DOC per liter of LB or $120 \mu \mathrm{g}$ of neomycin per $\mathrm{ml}$ of YEM. The ability to grow in both media was considered evidence of dual occupancy or due to a possible reversion of the mutant. Competitiveness for nod- ulation was assessed by the proportional representation of each strain in the nodules relative to its proportional representation in the inoculum (2).

LPS immunoreactivity. Antiserum preparation and Ig purification. Antiserum to $\mathrm{Rm} 1021$ late-log-phase cells was prepared as described by Somasegaran and Hoben (55). Immunoglobulins (Igs) from the crude serum were purified by ammonium sulfate precipitation and DEAE-cellulose chromatography as previously described by Clark and Adams (22). Igs were monitored during the purification procedure by cellulose acetate electrophoresis.

(i) ELISA. The ability of Rm2011 LPS and Rm6963 LPS to bind homologous anti- $R$. meliloti Igs was estimated by an enzyme-linked immunosorbent assay (ELISA). Polystyrene multiwell plates were incubated for $1 \mathrm{~h}$ at $37^{\circ} \mathrm{C}$ and overnight at $4^{\circ} \mathrm{C}$ with $100 \mu \mathrm{l}$ of selected fractions eluted from the Sepharose CL-4B column per well. The plates were then pretreated for $1 \mathrm{~h}$ at $37^{\circ} \mathrm{C}$ with $100 \mu \mathrm{l}$ of $3 \%$ skim milk per well in phosphate-buffered saline (PBS) to prevent nonspecific binding of the antiserum to the plate. After washing, 100 $\mu l$ of anti-R. meliloti 1021 rabbit gamma globulin (dilution, $1: 100$ ) per well was added, the solution was incubated for 1 $h$ at $37^{\circ} \mathrm{C}$ and washed, and $100 \mu$ l of goat anti-rabbit IgG conjugated to horseradish peroxidase $(1: 1,000$ [Sigma]) per well was added and incubated for $1 \mathrm{~h}$ at $37^{\circ} \mathrm{C}$. Antibodies were always diluted in $3 \%$ skim milk-PBS. The substrate for color development was a solution of $2 \mathrm{mg}$ of $o$-phenylenediamine (Sigma) per $\mathrm{ml}$ in $0.1 \mathrm{M} \mathrm{Na} \mathrm{NPO}_{4}-0.1 \mathrm{M}$ sodium citrate-100 $\mu$ l of $\mathrm{H}_{2} \mathrm{O}_{2}(30 \%)$ ( $\left.\mathrm{pH} 5\right)$ per liter. The reaction was initiated by the addition of $100 \mu$ l of freshly prepared substrate to each sample, which was incubated for 5 to 15 min at room temperature, and stopped with the addition of $100 \mu$ l of $4 \mathrm{~N} \mathrm{H}_{2} \mathrm{SO}_{4}$. The $A_{490}$ of the $o$-dinitrobenzene product in the supernatant fluid was measured against a buffer blank which had been subjected to the entire ELISA protocol.

(ii) Immunoblotting. For detection of LPS subfractions that supported a positive reaction in ELISA, LPS samples were electrophoretically fractionated by SDS-PAGE, transferred to nitrocellulose, and analyzed by immunoblotting as described by Strum et al. (57). The reactivity of each component was deduced by comparison of the immunoblotting with the silver-stained pattern of a duplicate gel.

\section{RESULTS}

Isolation of the mutant Rm6963. Mutants of Rm2011 were obtained by general Tn 5 mutagenesis with plasmid pSUP 1011. About 10,000 neomycin-resistant transconjugants were transferred to TY medium and Vincent minimal medium. Among the Tn5 mutants isolated, 91 showed an altered colony morphology. One of these mutants, Rm6963, produced rough colonies. The mutant was more sensitive to hydrophobic conditions when tested on LB medium containing appropriate amounts of DOC ( 1 g/liter) or SDS $(0.1$ g/liter). Colony morphology and sensitivity to DOC and/or SDS suggested the presence of an altered LPS in Rm6963. General transduction with phage $\phi M 12$ showed that neomycin resistance was always cotransducible with sensitivity to hydrophobic compounds. This indicated that Tn5 was responsible for the mutant phenotype.

Analysis of crude hot phenol-water extracts from Rm2011 and Rm6963 on Sepharose CL-4B. Hot phenol-water extracts obtained from strains Rm2011 and Rm6963 were separately chromatographed in Sepharose CL-4B, and the collected fractions were assayed for hexose and KDO (Fig. 1). Three 


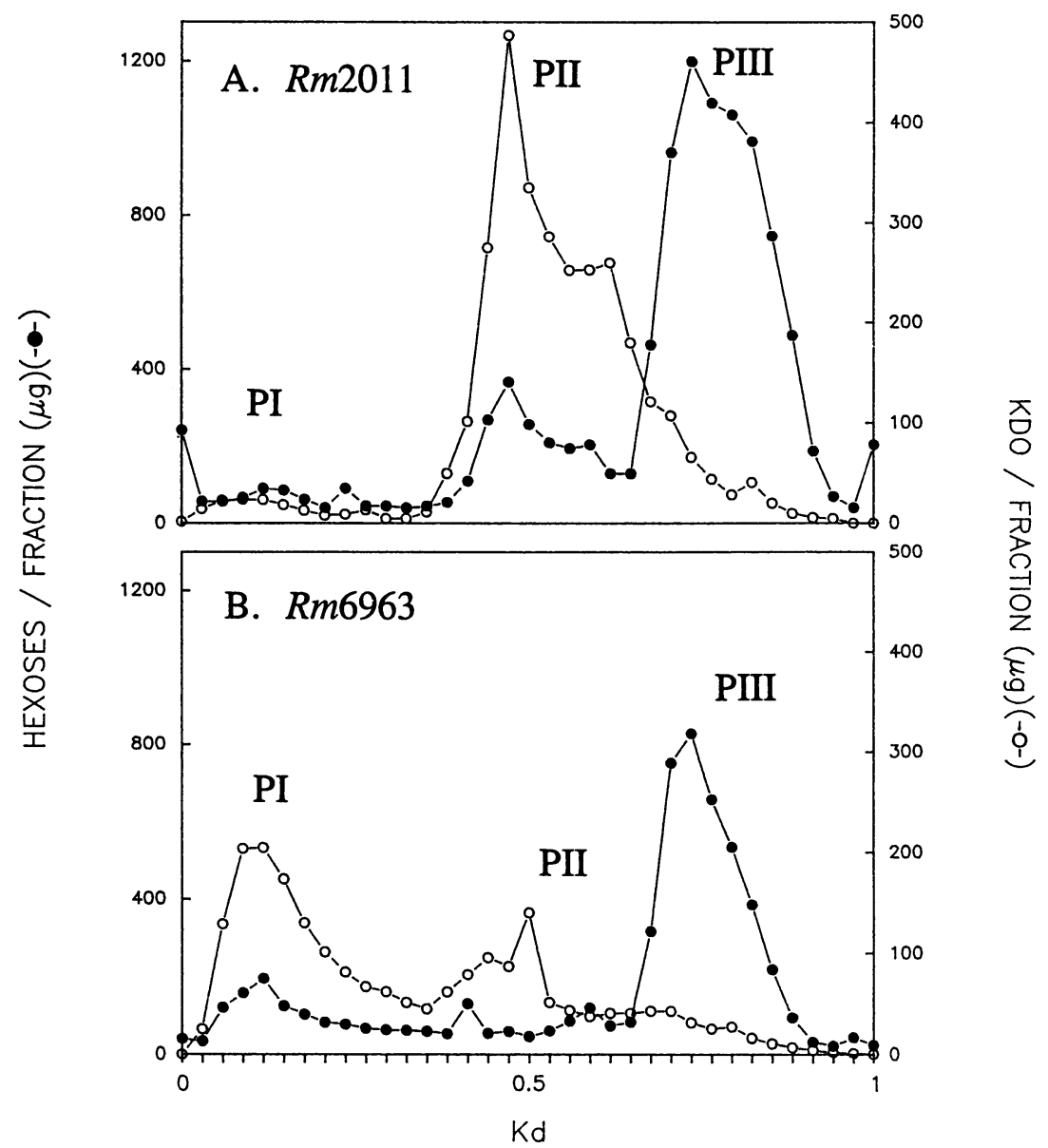

FIG. 1. Sepharose CL-4B chromatograms of hot phenol extracts of strains Rm2011 (A) and Rm6963 (B). Each sample, containing 6 to 12 $\mathrm{mg}$ as hexoses, was applied to the column in a volume of approximately $1.5 \mathrm{ml}$ and run at $4^{\circ} \mathrm{C}$ (column diameter, $2 \mathrm{~cm} ;$ height, $60 \mathrm{~cm}$ ). The flow rate was ca. $8 \mathrm{ml} / \mathrm{h}$. Fractions of $4 \mathrm{ml}$ each were collected and analyzed for the presence of hexose (O) and KDO (O) as described in Materials and Methods. The void volume $\left(V_{0}\right)$ and included volume $\left(V_{i}\right)$ for calculation of distribution coefficients $K_{d}\left[K_{d}=\left(V_{\text {sample }}-V_{0}\right) / V_{i}\right]$ were measured by using $1.5 \mathrm{ml}$ of a mixture of blue dextran $(0.05 \mathrm{~g} / \mathrm{ml})$ and $\mathrm{CaCl}_{2}(0.5 \mathrm{~g} / \mathrm{ml}) . V_{0}, 66 \mathrm{ml} ; V_{i}, 136 \mathrm{ml}$.

peaks containing hexose were eluted, of which peaks PI $\left(K_{d \max }=0.1\right)$ and PII $\left(K_{d \max }=0.5\right)$ contained KDO. The presence of KDO in peak PIII from both strains appeared to be due to the tailing of peak PII. The results suggest that in this chromatographic system, the LPS of Rm2011 was distributed in both PI and PII (similar profiles were also observed for crude LPS of the homologous strain RmL5-30, indicating that this pattern may be common to other wild- type $R$. meliloti strains). However, the hot phenol-water extracts from Rm6963 and Rm2011 showed different behaviors. In the mutant, the KDO content of peak PI (nearly $60 \%$ of the total) was considerably more than that of Rm2011 (5\% of the total) (Table 2). This finding suggests an LPS alteration in Rm6963 detected as an increase in the KDO-containing material eluting near the void volume of the column. The shift in the elution of KDO corresponded to an increase in

TABLE 2. Analysis of hexose, KDO, and hydrophobic properties of peaks PI, PII, and PIII after chromatography of bacterial crude phenol extracts in Sepharose CL-4B

\begin{tabular}{|c|c|c|c|c|c|c|c|c|c|}
\hline \multirow{3}{*}{ LPS origin } & \multicolumn{9}{|c|}{$\mu \mathrm{g} /$ peak $(\%)^{a}$} \\
\hline & \multicolumn{3}{|c|}{ PI $\left(K_{d}=0-0.34\right)^{b}$ for: } & \multicolumn{3}{|c|}{ PII $\left(K_{d}=0.35-0.63\right)^{b}$ for: } & \multicolumn{3}{|c|}{ PIII $\left(K_{d}=0.64-1\right)^{b}$ for: } \\
\hline & Hexoses & KDO & $R^{c}$ & Hexoses & KDO & $R^{c}$ & Hexoses & KDO & $\overline{R^{c}}$ \\
\hline Rm2011 & $918(9)$ & $156(5)$ & 0 & $1,832(18)$ & $2,310(75)$ & 1.4 & $7,624(73)$ & $626(20)$ & 0 \\
\hline Rm6963 & 1,128 (19) & $1,227(59)$ & 1.2 & 787 (13) & $617(29)$ & 0.2 & $4,036(68)$ & $253(12)$ & 0 \\
\hline
\end{tabular}

${ }^{a}$ Numbers in parentheses correspond to percentages of the total seeded material.

${ }^{b}$ For definition of $K_{d}$, see Results.

c The hydrophobicity of each sample was estimated with the $R$ coefficient by using the optical probe merocyanin 540 as follows: $R=\left(\mathrm{OD}_{567} / \mathrm{OD}_{500}\right)_{\mathrm{sample}}-$ $\left(\mathrm{OD}_{567} / \mathrm{OD}_{500}\right)_{\text {buffer. }}$ Optical densities were measured in the presence of merocyanin (final concentration, $5 \mu \mathrm{g} / \mathrm{ml}$ ). $R$ values were obtained for fractions at the maximum of each peak. 
A

B

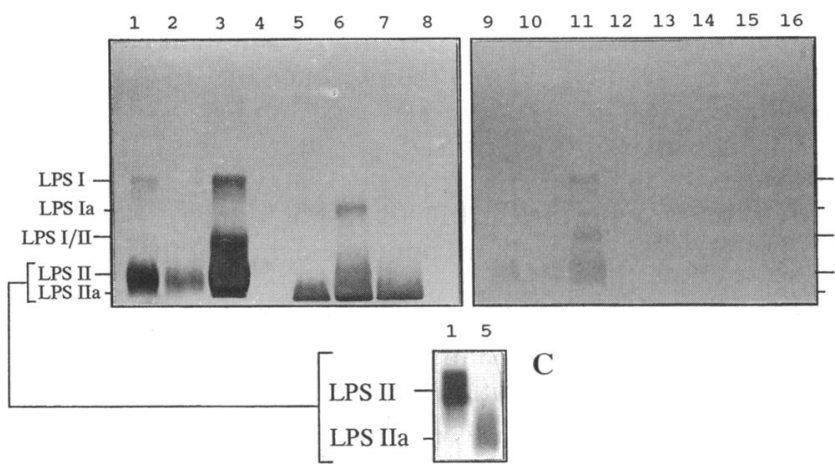

FIG. 2. SDS-PAGE (A and C) and immunoblotting (B) of chromatographed hot phenol-water extracts from strains Rm2011 and Rm6963. Slabs from panels A and B $(7$ by $8 \mathrm{~cm}$ ) were run in a Mini-Protean II 2-D cell (Bio-Rad). Immunoblotting of panel B was carried out with a gel duplicating the samples from the one shown in panel $\mathrm{A}$ and with purified $\mathrm{Ig}$ from a rabbit antiserum against $\boldsymbol{R}$. meliloti $\mathrm{Rm} 1021$ as first antibody. The well samples were as follows: lane 1, Rm2011 crude hot phenol-water extract; lane 2, Rm2011 PI; lane 3, Rm2011 PII; lane 4, Rm2011 PIII; lane 5, Rm6963 crude hot phenol-water extract; lane 6, Rm6963 PI; lane 7, Rm6963 PII; lane 8, Rm6963 PIII. Each well contained $1 \mu \mathrm{g}$ (as hexoses) of the corresponding fraction. Panel C shows details of bands LPS II and LPS IIa after being run in a gel $(12$ by $13 \mathrm{~cm})$ to improve resolution $(4$ $\mu \mathrm{g} / \mathrm{well})$. The positions of the bands are indicated in the left margin.

the $R$ hydrophobicity coefficient of peak PI (Table 2). The high absorption of the optical probe merocyanin 540 at 567 $\mathrm{nm}$ might be attributed to the possible presence of lipid A, a potential enhancer of the basal hydrophobicity of the buffer EDTA-triethylamine. A high $R$ coefficient was measured in peak PII of strain Rm2011, correlating again with the presence of KDO. No differences between both strains were evident in peak PIII.

SDS-PAGE analysis. Crude and chromatographically purified LPS extracts were analyzed by SDS-PAGE. Figure 2A shows the silver-stained banding pattern of crude hot phenol-water extracts from Rm2011 and Rm6963 (lanes 1 and 5, respectively). According to criteria already applied to other rhizobial LPS $(6,18)$, components in the gel were designated LPS I or LPS II according to their electrophoretic mobilities.
Marked differences among the silver-stained patterns of parent and mutant strains were observed. The mutant LPS lost the band corresponding to component LPS I which is present in the parental LPS but showed a new component (marked LPS Ia) which migrated faster to the anode. Differences were also evident in LPS II. A broad band marked LPS IIa had a faster mobility than its apparently homologous wild-type component LPS II. As shown in Fig. 2C, LPS II and LPS IIa components were clearly resolved with long slab gels. Assuming that these components correspond to lipid A and core, the mutant should be affected in at least one of these LPS structural regions. The increase in electrophoretic mobilities in both LPS I and LPS II suggests a decrease in the length or an increase in the charge of mutant LPS molecules. Besides these changes, other components found in the LPS of Rm2011 were located between LPS I and LPS II (marked LPS I/II) and were not observed at the same position in Rm6963 LPS. In our experimental conditions, LPS components did not resolve in clusters of several bands or exhibit patterns of regular periodicity characteristic of the LPS heterogeneity described with other rhizobia (12).

Components of the isolated peaks PI, PII, and PIII were also analyzed by SDS-PAGE (Fig. 2A, lanes 2 to 4 and 6 to 8). As expected from the KDO levels of the fractions (Fig. 1), silver staining confirmed that most of the LPS from Rm2011 corresponded to peak PII, while LPS from Rm6963 distributed between both peaks PI and PII (all samples were loaded in amounts with equivalent hexose contents). Since the substrate for the LPS silver staining appears to be mainly the lipid A (39), a coincidence between the best-stained fractions and those with a higher $R$ coefficient was expected.

LPS immunocharacterization. The immunocharacterization of LPS was carried out by immunoblotting and ELISA. Fractions corresponding to the maxima of peaks PI, PII, and PIII were tested in their reactivities against purified anti- $R$. meliloti Ig. Although the reactivities of peaks PI and PII from $\mathrm{Rm} 2011$ correlated with the respective KDO contents (Fig. 2B, lanes 10 and 11), mutant LPS samples were completely unreactive (Fig. $2 B$, lanes 13 to 16 ). This could be confirmed by ELISA (Fig. 3). Under our experimental conditions, the ELISA was highly sensitive, detecting in the case of peak PII from Rm2011 up to 20 to $100 \mathrm{pg} /$ well (as hexoses). The absence of reaction in LPS samples of Rm6963 could be confirmed at this level. Immunoreactivity was strictly dependent on the presence of wild-type LPS.
PI

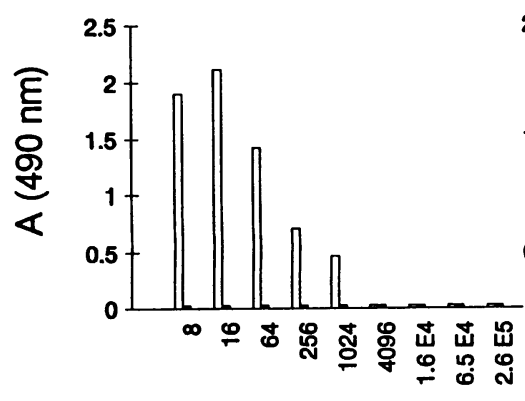

PII

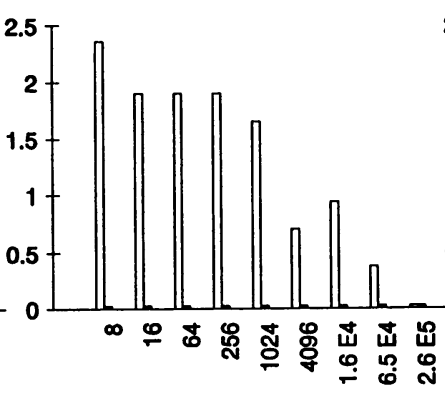

PIII

\section{dilution factor}

FIG. 3. Reactivity in ELISA of peaks PI, PII, and PIII from strains Rm2011 and Rm6963 against purified Igs from an anti-R. meliloti antiserum. Fractions corresponding to the maximum of each peak (Fig. 1) were diluted as indicated and used as antigens. The ELISA was carried out as described in Materials and Methods. 

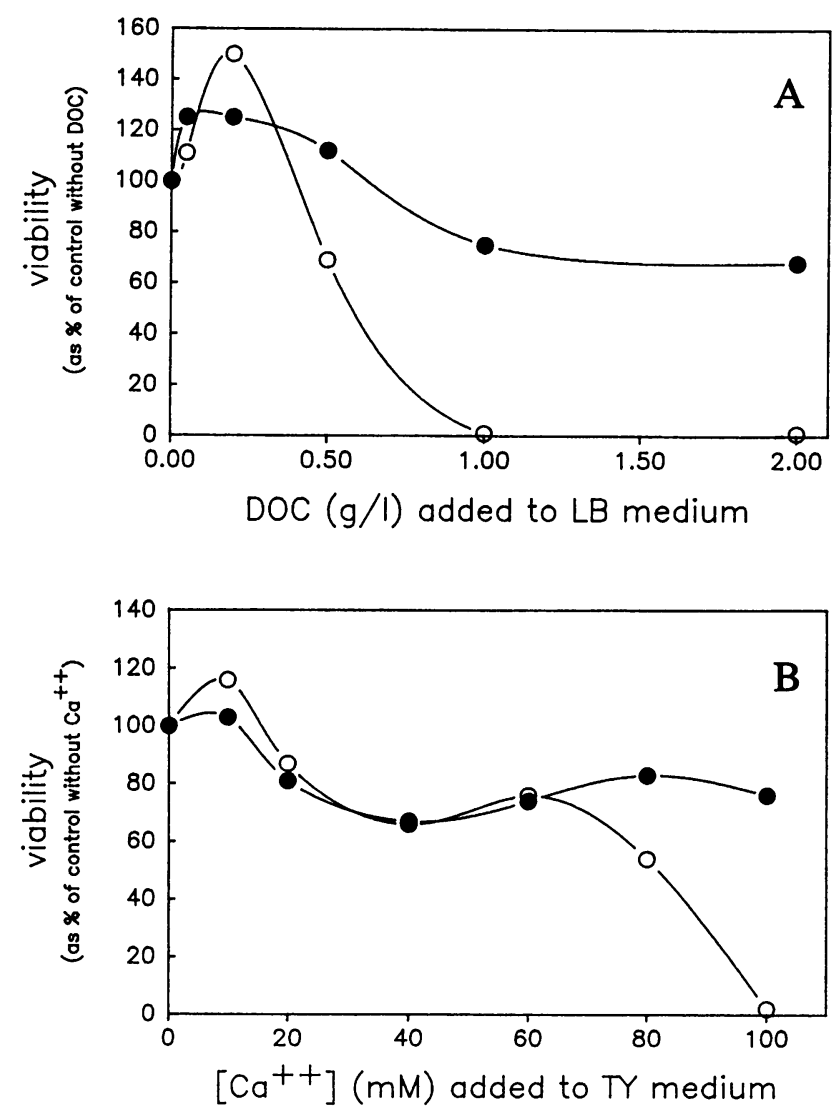

FIG. 4. Dependence of the viability of strains $R \mathrm{~m} 2011(0)$ and Rm6963 (O) on the presence of increasing concentrations of DOC (A) or $\mathrm{Ca}^{2+}$ (B). An appropriate dilution of bacterial cultures in the log phase of growth containing $10^{2}$ bacteria was plated in LB agar-DOC and TY agar- $\mathrm{Ca}^{2+}$, and the number of bacterial colonies was determined 4 to 7 days later. The results are expressed as percentages of colonies for a given DOC or $\mathrm{Ca}^{2+}$ concentration with respect to the control medium without any addition.

The total loss of reactivity in the mutant (all bands) indicated that LPS of Rm6963 had lost antigenic structures present in the wide range of molecular forms of Rm2011 LPS (LPS I, LPS II, and LPS I/II).

The hexose-rich and KDO-poor material of peak PIII present in both crude LPS preparations was neither silver stained nor recognized by the homologous Ig (Fig. 2B, lanes 12 and 16). As shown in Table 2, peak PIII did not show the hydrophobic character detected in peak PI of the mutant and peak PII of the wild type with the optical probe merocyanin 540 , suggesting the absence of LPS in this fraction. In other rhizobia, material eluting at the position of PIII is often $\beta$-(1-2)-glucan.

Sensitivity to hydrophobic compounds. The growth of mutant and wild-type bacteria in the presence of DOC (or SDS) was used to characterize the outer membrane as a barrier to hydrophobic compounds $(23,52)$. The mutant was more sensitive to increases in hydrophobicity of the medium than the wild type (Fig. 4A). When LB medium (pH 6.80 to 6.85) was supplemented with concentrations of DOC of $1 \mathrm{~g} /$ liter or higher, only Rm 2011 was able to grow. The mutant exhibited a survival of $50 \%$ at about $0.7 \mathrm{~g}$ of DOC per liter. Apparent survival rates with values higher than $100 \%$ at very low DOC concentrations were attributed to disruption of cell aggre- gates caused by mechanic spreading during plating. Sensitivity to DOC was extremely dependent on the $\mathrm{pH}$. At $\mathrm{pHs}$ higher than 7.0 (i.e., 7.4 to 7.5), the LPS mutant could grow (though deficiently) even in the presence of 1 to $2 \mathrm{~g}$ of DOC per liter.

The addition of $0.1 \mathrm{~g}$ of SDS per liter to the LB medium also clearly inhibited the growth of Rm6963 and to some extent the growth of Rm2011 (data not shown). Both DOC and SDS could be used for counterselection of the wild-type strain against the mutant.

Sensitivity to high calcium concentrations. Strain Rm6963 showed a decreased resistance to growth in TY medium with high calcium concentrations (Fig. 4B). Increases in the $\mathrm{CaCl}_{2}$ concentration diminished the rate of bacterial growth. Negligible growth occurred at $100 \mathrm{mM}$, with colonies developing only after 2 weeks. This alteration in the cell growth physiology may be derived from the altered LPS, as reported for some LPS mutants of $R$. leguminosarum bv. viciae (36).

Nodulation of $R$. meliloti 6963 . Nodulation assays in glass tubes containing nitrogen-free Jensen medium showed that the mutant produced apparently normal nitrogen-fixing nodules able to support growth of the inoculated plants. However, when plants were grown in plastic pouches and were carefully analyzed, nodules induced by Rm6963 developed the characteristic pink coloration of normal indeterminate nodules several days after the appearance of nodules formed by wild-type bacteria. Plants inoculated with the mutant were smaller and yellowed during the first 2 to 4 weeks of growth. These plants showed a marked reduction in the fresh weight of their green tissues (ca. 30\%) 3 weeks after inoculation. This symbiotic phenotype paralleled the progress of nitrogenase expression. Acetylene reduction assays showed that, for example, at 20 days postinoculation, the rate of fixation was 35 and $45 \mathrm{nmol}$ of $\mathrm{C}_{2} \mathrm{H}_{2} \cdot$ plant $^{-1} \cdot \mathrm{h}^{-1}$ for plants inoculated with the mutant and wild type, respectively. However, plants recovered later in their development with an appearance that became comparable to that of the control inoculated with Rm2011.

Time course of nodulation. We studied the ability of parent and mutant strains to nodulate alfalfa on primary and lateral roots (Fig. 5). Although there were no appreciable differences in the speed with which nodules emerged on primary roots (slope in Fig. 5 graph), nodules induced by Rm6963 started to appear 4 days later than wild-type nodules (Fig. $5 A)$. In contrast, the time rate of nodule emergence on lateral roots was consistently lower for plants inoculated with wild-type bacteria (Fig. 5B). After about 12 days postinoculation, nodules induced by Rm6963 in lateral roots increased drastically and reached levels that were higher than those obtained with Rm2011. At 1 month postinoculation, the number of nodules induced by the mutant on primary roots ranged between 40 and $100 \%$ of the number of wild-type nodules; on secondary roots, however, nodulation was up to fivefold higher (Fig. 5B).

Distribution of nodules on primary roots. Figure 6 shows the distribution of nodules on primary roots 9 days postinoculation. Both strains were able to nodulate essentially the same region of the roots. Since nodules induced by Rm6963 emerged later, total nodulation on the primary root during the first week postinoculation was decreased, and this was reflected by the number of nodules formed at different locations on the primary root (Fig. 6). In addition, we have observed that later than 15 days after inoculation, mutant and wild-type nodule distribution profiles were comparable. The observation that alfalfa primary roots were nodulated by 

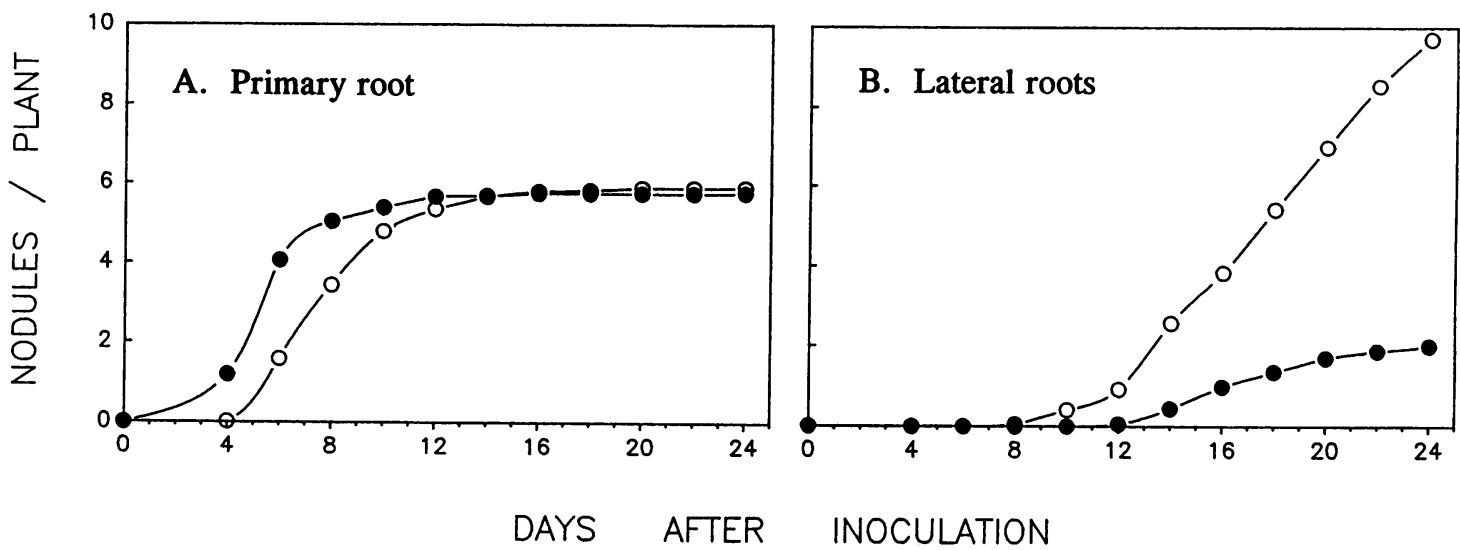

FIG. 5. Kinetics of nodulation of alfalfa roots by strain Rm2011 and its LPS mutant, Rm6963. Sets of 84 and 73 plants were inoculated with $1.5 \times 10^{6}$ bacteria per plant of strain $\operatorname{Rm} 2011(O)$ and $R \mathrm{~m} 6963(O)$, respectively. Nodules on primary (A) and secondary (B) roots were periodically scored at regular intervals of time. Results are given as average numbers of nodules per plant and are representative of three experiments. Nodulation of the mutant was more pronounced in this experiment than in the other two.

both strains in the same regions suggests that strain Rm6963 behaves normally during preinfection.

Split-root experiments. We examined the ability of Rm6963 to elicit systemic feedback control of nodulation in alfalfa. In split-root assays, prior inoculation of one side of a split-root system with Rm6963 suppressed nodulation of a wild-type bacterium on the other side by $44 \%$ (Table 3 ). Prior inoculation with $\mathrm{Rm} 2011$ resulted in stronger inhibition of nodulation (93\%). Results show that mutant Rm6963 had a decreased ability to autoregulate nodule number, probably

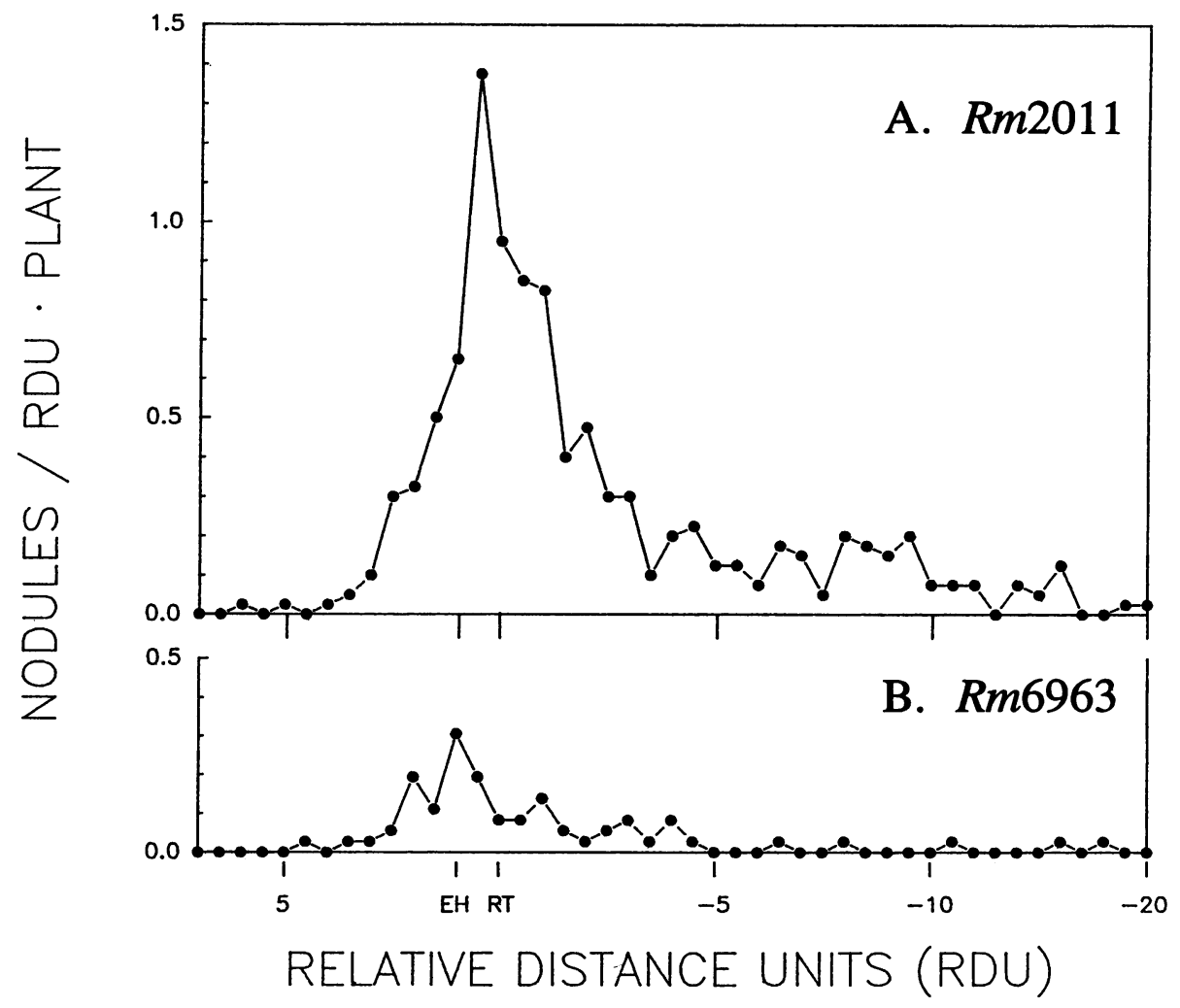

FIG. 6. Distribution profiles of nodules generated on alfalfa roots inoculated with Rm2011 (A) or with its LPS mutant, Rm6963 (B). Sets of 80 and 72 plants were inoculated with strain $\mathrm{Rm} 2011\left(2.5 \times 10^{6} \pm 0.2 \times 10^{6}\right.$ bacteria per plant) and strain $\mathrm{Rm} 6963\left(1.4 \times 10^{6} \pm 0.3 \times 10^{6}\right.$ bacteria per plant), respectively. Profiles correspond to an early-nodule scoring 9 days after inoculation. The relative distance of each nodule was expressed as a percentage of the distance of root tips (RT) to the smallest emergent root hairs (EH) determined for each plant. The average distance of root tips to emergent root hairs was $2.9 \pm 1.2 \mathrm{~mm}$ for this experiment. Since the average rate of root elongation was 0.5 $\pm 0.004 \mathrm{~mm} / \mathrm{h}, 1$ relative distance unit (RDU) is equivalent to approximately $6 \mathrm{~h}$ of root growth. The direction of root growth is from left to right. The results are from a representative experiment among three. 
TABLE 3. Effect of prior inoculation with Rm2011 or its LPS mutant, Rm6963, on one side of a split-root system, on nodulation on the second side by an indicator strain $^{a}$

\begin{tabular}{llrr}
\hline \multirow{2}{*}{$\begin{array}{c}\text { Location and inoculum } \\
\text { type for side A }\end{array}$} & \multicolumn{1}{c}{ Avg no. of nodules/lateral root for: } & \multicolumn{1}{c}{$\begin{array}{c}\text { Relative nodulation } \\
\text { in side B }\end{array}$} \\
\cline { 2 - 3 } Above root tips & \multicolumn{1}{c}{ Side A $^{b}$} & $2.23(1.63-2.92)^{29}$ & 100 \\
$\quad$ Sham & $0^{32}$ & $0.15(0.04-0.35)^{33}$ & 7 \\
Rm2011 (parental) & $2.44(1.94-3.01)^{30}$ & $1.25(0.80-1.78)^{28}$ & 56 \\
Rm6963 (LPS mutant) & $0.43(0.25-0.65)^{37}$ & & \\
Whole lateral root & & $4.01(3.12-5.01)$ & 100 \\
Sham & $0.02(0-0.14)$ & $0.39(0.16-0.71)$ & 10 \\
Rm2011 (parental) & $3.88(3.02-4.85)$ & $2.05(1.42-2.80)$ & 51 \\
Rm6963 (LPS mutant) & $1.34(0.90-1.87)$ & & \\
\hline
\end{tabular}

${ }^{a}$ Split roots were inoculated at the time of marking root tip 1 on side A with Hoagland mineral solution (sham), with $3.7 \times 10^{6}$ bacteria of strain Rm6963 per root, or with $8.6 \times 10^{6}$ bacteria of strain $\mathrm{Rm} 2011$ per root as indicated, and then inoculated $24 \mathrm{~h}$ later (root tip 2) on the opposite side (side B) with $7.2 \times 10^{6}$ bacteria of the indicator strain Rm1021 per root. The average distance between root tip 1 and root tip 2 was $8.3 \pm 1.5 \mathrm{~mm}$. Mean numbers of nodules are based on the square root transformation, with confidence limits of $95 \%$ in brackets. Superscripts are the numbers of lateral roots per side examined.

b Above root tip 1 .

${ }^{c}$ Above root tip 2.

resulting from its delayed nodulation. The inhibitory activity of nodulation in side $B$ correlated with the number of nodules formed in the initially susceptible region of the roots at the time of the first inoculation in side $A$.

Nodule occupancy in coinoculation experiments. While both wild-type and mutant bacteria appear to initiate infections at the same time (Fig. 6), nodules induced by the mutant strain emerged later than those induced by the wild type (Fig. 5). This suggests that mutant Rm6963 was probably affected in its ability to develop infections at a normal rate rather than in its timing in initiating infections. Symbiotic deficiencies of Rm6963 were clearly reflected in its altered ability to compete for nodule occupancy. A preliminary experiment in plastic pouches with $10^{6}$ bacteria of each strain per plant in the inoculum revealed that $\mathrm{Rm} 2011$ occupied all analyzed uppermost nodules on the primary root. In similar experiments (but using plants grown in pots), we examined nodule occupancy within a range of mutant-to-wild-type-bacteria ratios (Fig. 7). When mutant and wild-type inocula were equivalent in number, only Rm2011 was found in the uppermost nodules examined. One hundred times more mutant bacteria was necessary to produce a 1:1 nodule occupancy ratio (Fig. 7A). Analysis of secondary-root nodules gave similar results (Fig. 7B). Competitiveness was estimated quantitatively by using a previously described mathematical model (2) (Fig. 8). Double-log representation of the ratio of the cells of each strain in nodules $(P)$ to those in the inocula (I) consistently fitted the experimental data $(r=0.99)$. The competitive index $C_{2011: 6963}$ (for strain $\mathrm{Rm} 2011$ to $\mathrm{Rm6963)}$ had a positive value of 1.52 , indicating that if $I_{2011}=I_{6963}$, a nodule occupancy ratio of $P_{2011}$ to $P_{6963}$ near 30:1 should occur. On the other hand, to reach a value of $P_{2011} / P_{6963}=1$, an $\mathrm{I}_{2011}$-to- $\mathrm{I}_{6963}$ inoculum ratio of 1:100 had to be used.

\section{DISCUSSION}

We examined the role of LPS during the symbiotic association of $\boldsymbol{R}$. meliloti with alfalfa. Following random transposon Tn5 mutagenesis of wild-type bacteria, mutant Rm6963 was isolated because of its rough colony morphology on TY agar medium. The abnormal sensitivity to growth in the presence of detergents suggested initially that the mutant could be affected in its LPS. A careful analysis revealed that the mutant was more sensitive to the hydrophobic compounds DOC and SDS. Transduction of the $\mathrm{Nm}^{\mathrm{r}}$

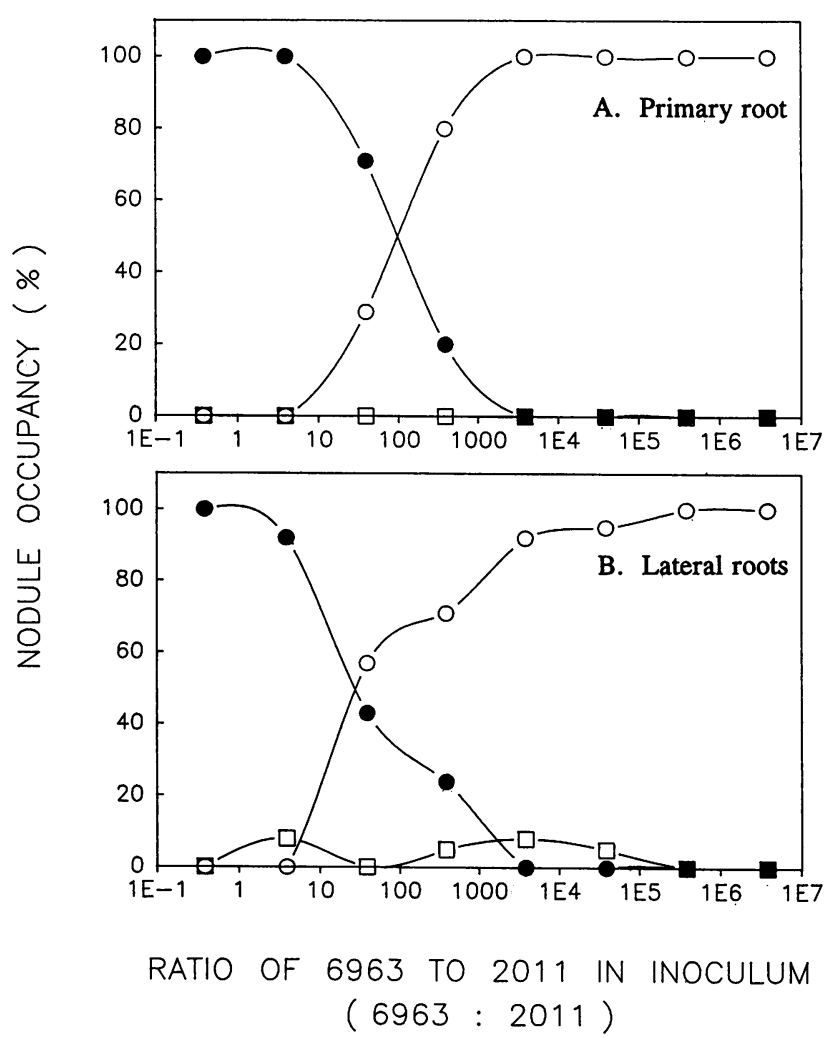

FIG. 7. Competition experiments for nodulation of alfalfa with Rm2011 and Rm6963 as inoculant over a range of bacterial ratios. The occupancy of nodules by each strain in primary roots $(A)$ and lateral roots (B) was determined by using DOC and neomycin as resistance markers of strains $R \mathrm{~m} 2011(\bullet)$ and $R \mathrm{~m} 6963(O)$, respectively (see Materials and Methods). The intersections of both curves in the graphs indicate the ratios (on the abscissas) of bacteria with which a 50\% occupancy was obtained. Bacterial growth in both media ( $\square$ ) was considered an indication of cooccupancy or partial reversion of the mutant. This was observed only in secondary-root nodules and occurred in less than $10 \%$ of the number of nodules examined. 6963:2011, Rm6963 to Rm2011. 


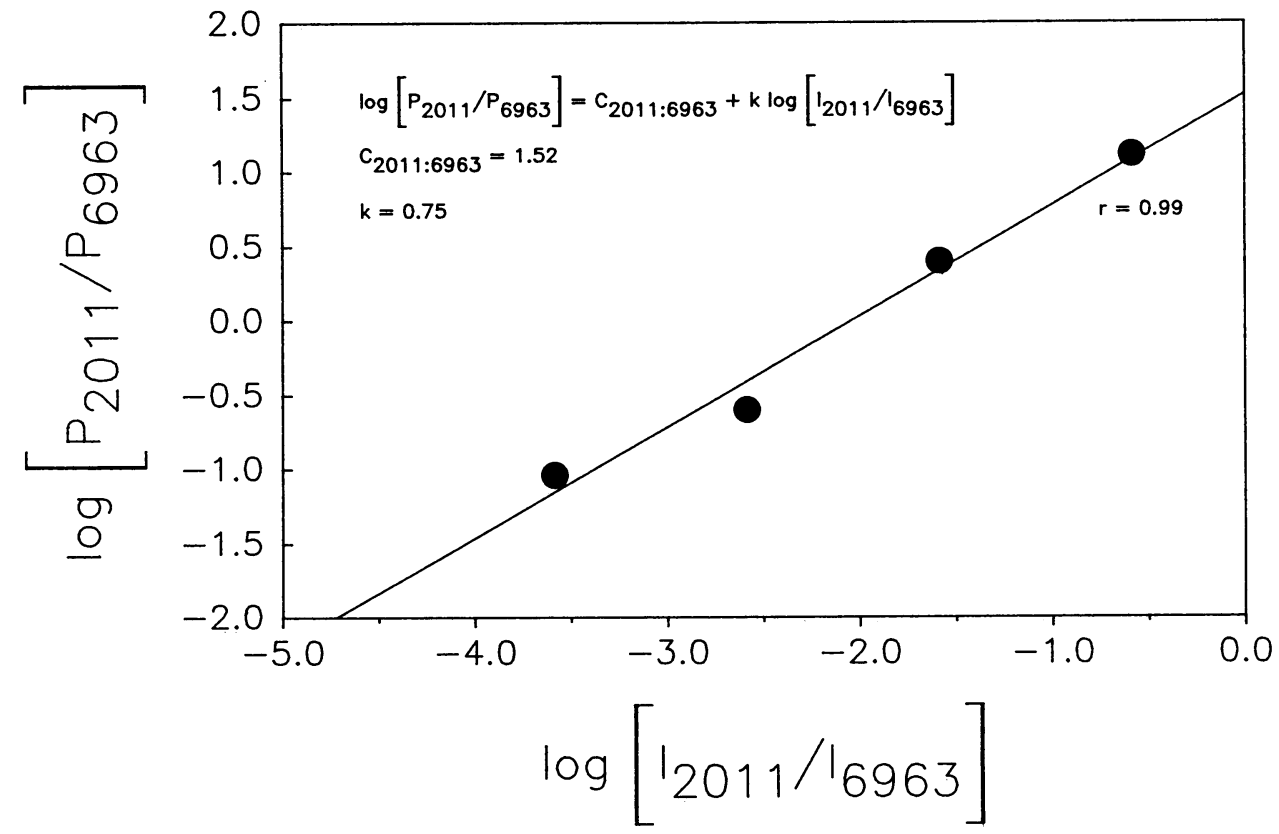

FIG. 8. Graphic estimation of the relative competitiveness of strains Rm2011 and Rm6963. A function of the nodule occupancies of the strains was regressed as a function of the inoculum ratio as previously published (2). The ratio of the proportion of nodules in the primary root occupied by each strain $\left(P_{2011}: P_{6963}\right)$ was logarithm transformed and was regressed on the logarithm of the ratio of the two strains in the inoculum $\left(I_{2011}: I_{6963}\right)$ as follows: $\log \left(P_{2011} / P_{6963}\right)=C_{2011}: C_{6963}+k \log \left(I_{2011} / I_{6963}\right)$. The competitiveness index $\left(C_{2011}: C_{6963}\right)$ had a positive value, indicating that strain $R m 2011$ occupies a larger proportion of the nodules than strain $R m 6963$ when $I_{2011}=I_{6963}$. A ratio of $P_{2011} / P_{6963}$ $=1$ was reached with an inoculum ratio of $I_{2011}$ to $I_{6963}$ near $1: 100$.

marker proved that this mutant phenotype was caused by the transposon insertion.

Gel permeation of hot phenol-water extracts in Sepharose CL-4B separated three fractions in both strains and clearly showed that Rm6963 in fact carried an altered LPS. However, although LPS eluted with the first two fractions in both the wild-type and the mutant strain, extracts from Rm6963 showed an increased proportion of KDO-containing material near the void volume (PI). The appearance of this KDOpositive material strongly suggests that mutant LPS could form larger aggregates than wild-type molecules, probably because of a shorter LPS saccharide region. In other gramnegative bacteria, LPS with a short saccharide moiety formed large macromolecular aggregates in solution (30). Electrophoretic mobilities confirmed that LPS components from Rm6963 had lower molecular weights than homologous components in the wild type. The fact that by SDS-PAGE, component LPS II (LPS IIa in the mutant) was present in both PI and PII could derive from aggregates of this component ranging broadly in size and containing common molecular species.

Results from ELISA and immunoblotting assays showed that LPS structures recognized by the homologous serum in the wild-type LPS were not detected in the mutant. Since the immunoreactivity was monitored with Igs from a polyclonal antiserum, we do not know whether the Tn 5 insertion affected several epitopes simultaneously or a restricted number of highly immunodominant structures. Electrophoretic analysis of LPS II and LPS IIa showed that the Tn5 insertion altered both gel migration and immunoreactivity of this component in the mutant. If no pleiotropic effects are present, the changes that result in the shift from LPS II to LPS IIa may be the same ones that cause the shift from LPS
I to LPS Ia in the complete LPS forms. However, mutant LPS molecules can be altered in several regions. Formally, the total loss of immunoreactivity in the mutant LPS can be due to alterations in (i) epitopes common to LPS I and LPS II (i.e., core epitopes) or (ii) epitopes common to LPS I and LPS II and epitopes exclusive to LPS I. Alteration of epitopes present only in LPS I should have preserved the reactivity of LPS IIa. Our results show that a great proportion of the LPS immunoreaction is supported by LPS II. Surprisingly, no residual immunoreaction against the remaining LPS Ia in the mutant was detected. LPS Ia was expected to harbor a reactive $O$ antigen, as in other gramnegative bacteria. These results suggest that in fact the remaining LPS groups unaltered by the $\operatorname{Tn} 5$ mutation are weak antigenically in the wild type. On the other hand, the strong antigenic character of LPS II contrasts with the behavior of LPS from S-type bacteria, in which antibodies are raised mainly against the $O$ antigen. The immunoreaction of $R$. meliloti LPS resembles in a sense the immunochemistry of R-type mutants from members of the family Enterobacteriaceae. These mutants and $R$. meliloti have LPS with high $\mathrm{KDO} /$ hexose ratios (12). In $R$. meliloti, however, we observed a marked antigenicity of LPS II occurring even in the presence of the larger LPS I forms.

In studying the role of LPS in symbiosis, we found that nodules formed by strain Rm6963 emerged later than those formed by the parent. However, both strains induced nodules to appear in the same locations along the primary roots and to emerge at comparable rates. This suggests that the mutation in strain Rm6963 did not delay the responsiveness of the host to the infecting bacteria or reduce the speed with which new infections occurred. The delay in nodule emergence suggests that although mutant bacteria were able to 
reach the infectible sites at the right time, it took an additional amount of time for the infection sites to become active or for the actual infections to start developing. In experiments in which nodulation of the mutant was lower than that of the wild type, a lower number of infections may have occurred. However, the timing at which infections followed root development was unaltered and paralleled the wild-type behavior.

The impaired-nodulation phenotype of Rm6963 appears to compromise its ability to compete for nodulation with wildtype bacteria. Inoculum ratios favoring the mutant by 100:1 were required to obtain an equal level of nodule occupancy. With equivalent numbers of competing bacteria, wild-type $\boldsymbol{R}$. meliloti infected the roots as if nodulation occurred virtually in the absence of the mutant. In these circumstances, the wild type had the symbiotic advantage of evoking first the autoregulatory response that controls nodulation (7) and of suppressing infections that were initiated later in root development as well as those that were already initiated but developed slowly.

We propose that the mutation in strain Rm6963 has altered the relationship between the time of establishment of first infections and the rate of appearance of autoregulation. Single-inoculation experiments and competition experiments suggest that nodules formed by Rm6963 in primary roots are subject to feedback control of nodule formation. However, the mutant bacteria were able to elicit only a defective autoregulatory response. The inoculation with Rm6963 on one side of a split-root system suppressed nodulation by a wild-type $R$. meliloti strain on the other side to a low extent when it was inoculated $24 \mathrm{~h}$ later. This deficiency resulted in a decrease in control of the number of lateral-root nodules. One month after inoculation, Rm6963 had formed approximately five times the number of nodules produced by the wild type. This effect is probably the expression of homeostasis to compensate for delayed nodulation. We have not examined whether the deficiency in autoregulatory responses is due to a defect in the stimulation of cortical-cell division, a step proposed to be relevant in nodulation control (9). It has been suggested that $R$. meliloti LPS could be involved in at least two stages during nodule formation (48). Our results suggest a role for LPS during the initial development of infections rather than during infection initiation. However, it must be considered that our evidence is based in one mutant and that it is the formal possibility that some of the mutant phenotypes are due to separate mutations in Rm6963. Even if all phenotypes are due to the same mutation, the symbiotic defects could arise, at least formally, from alterations in other molecules besides LPS. Further genetic characterization of this mutant is being studied.

Clearly, as indicated by the genetic background of Rm6963, LPS changes in this mutant are not related to the well-characterized lps $Z$ suppressor gene naturally absent in all SU-47-derivative strains (63). Another gene(s) must be involved. However, structures altered in Rm6963 might still be necessary for the expression of a chimeric $\mathrm{LpsZ}^{+}$phenotype in strain Rm2011. Other SU-47 LPS mutants carrying the lps $Z$ gene in an exoB background were still unable to fix nitrogen (62). New correlations between known lps genes and their functions during the interaction with the host plant should provide insight into the role of this bacterial surface component in symbiosis.

In summary, current evidence suggests that $R$. meliloti LPS is indeed involved in the symbiotic interaction with alfalfa by (i) providing a structure able to recognize the plant root during bacterial adsorption (41), (ii) modulating strain competitiveness during infection (the present work), and (iii) supporting a compatible association with the host plant independently or in conjunction with exopolysaccharide (48, $62,63)$. The goal is now to determine the molecular mechanism(s) of LPS action.

\section{ACKNOWLEDGMENTS}

We are greatly indebted to C. A. Fossati for invaluable help in setting up the immunotechnics, and we thank A. Campana for excellent technical assistance.

A.L. has been awarded fellowships from CONICET (Argentina) and from the Alexander von Humboldt Foundation AvH (Germany). G.F. is a member of the Research Career of CONICET (Argentina). This work was supported by grants from SECYT, CONICET, and CICBA (all from Argentina), SAREC Cooperation Project (from Sweden), and Stiftung Volkswagenwerk (I/64838 [from Germany]). Page charges for this article were paid by AvH.

\section{REFERENCES}

1. Bauer, W. D. 1981. Infection of legumes by rhizobia. Annu. Rev. Plant Physiol. 32:407-449.

2. Beattie, G. A., M. K. Clayton, and J. Handelsman. 1989. Quantitative comparison of the laboratory and field competitiveness of Rhizobium leguminosarum biovar phaseoli. Appl. Environ. Microbiol. 55:2755-2761.

3. Beringer, J. E. 1974. R factor transfer in Rhizobium leguminosarum. J. Gen. Microbiol. 84:188-198.

4. Bhuvaneswari, T. V., K. K. Mills, D. K. Christ, M. R. Evans, and W. D. Bauer. 1983. Effects of culture age on symbiotic infectivity of Rhizobium japonicum. J. Bacteriol. 153:443-451.

5. Borthakur, D., C. E. Barber, J. W. Lamb, M. J. Daniels, J. A. Downie, and A. W. B. Johnston. 1986. A mutation that blocks exopolysaccharide synthesis prevents nodulation of peas by Rhizobium leguminosarum but not of beans by Rhizobium phaseoli and is corrected by cloned DNA from Rhizobium or the phytopathogen Xanthomonas. Mol. Gen. Genet. 203:320-323.

6. Brink, B. B., J. Miller, R. W. Carlson, and K. D. Noel. 1990. Expression of Rhizobium leguminosarum CFN42 genes for lipopolysaccharide in strains derived from different $R$. leguminosarum soil isolates. J. Bacteriol. 172:548-555.

7. Caetano-Anollés, G., and W. D. Bauer. 1988. Feedback regulation of nodule formation in alfalfa. Planta 175:546-557.

8. Caetano-Anollés, G., and G. Favelukes. 1986. Quantitation of adsorption of rhizobia in low numbers to small legume roots. Appl. Environ. Microbiol. 52:371-376.

9. Caetano-Anollés, G., and P. M. Gresshoff. 1990. Early induction of feedback regulatory responses governing nodulation in soybean. Plant Sci. 71:69-81.

10. Caetano Anollés, G., A. Lagares, and W. D. Bauer. 1990. Rhizobium meliloti exopolysaccharide mutants elicit feedback regulation of nodule formation in alfalfa. Plant Physiol. 91:368374.

11. Carlson, R. W. 1982. Surface chemistry, p. 199-204. In W. J. Broughton (ed), Nitrogen fixation, vol. 2, Rhizobium. Clarendon Press, Oxford.

12. Carlson, R. W. 1984. The heterogeneity of Rhizobium lipopolysaccharides. J. Bacteriol. 158:1012-1017.

13. Carison, R. W., S. Kalembasa, D. Turowski, P. Pachori, and K. D. Noel. 1987. Characterization of the lipopolysaccharide from a Rhizobium phaseoli mutant that is defective in infection thread development. J. Bacteriol. 158:1012-1017.

14. Carison, R. W., U. Ramadas Bhat, and B. Reuhs. 1991. Rhizobium lipopolysaccharides: their structures and evidence for their importance in the nitrogen-fixing symbiotic infection of their host legumes, p. 39-50. In P. M. Gresshoff (ed), Current topics in plant molecular biology, vol. 1. Chapman and Hall, New York.

15. Carlson, R. W., R. E. Sanders, C. Napoli, and P. Albersheim. 1978. Host-symbiont interaction. III. Purification and partial characterization of Rhizobium lipopolysaccharides. Plant Physiol. 62:912-917.

16. Carison, R. W., R. Shatters, J.-L. Duh, E. Turnbull, B. Hanley, 
B. G. Rolfe, and M. A. Djordjevic. 1987. The isolation and partial characterization of the lipopolysaccharides from several Rhizobium trifolii mutants affected in root hair infection. Plant Physiol. 84:421-427.

17. Carlson, R. W., and M. Yadav. 1985. Isolation and partial characterization of the extracellular polysaccharides from fastgrowing Rhizobium japonicum USDA 205 and its Nod $^{-}$mutant, HC205, which lacks the symbiotic plasmid. Appl. Environ. Microbiol. 50:1219-1224.

18. Carrion, M., U. Ramadas Bhat, B. Reuhs, and R. W. Carison. 1990. Isolation and characterization of the lipopolysaccharide from Bradyrhizobium japonicum. J. Bacteriol. 172:1725-1731.

19. Cava, J. R., P. M. Elias, D. A. Turowski, and K. D. Noel. 1989. Rhizobium leguminosarum CFN42 genetic regions encoding lipopolysaccharide structures essential for complete nodule development on bean plants. J. Bacteriol. 171:8-15.

20. Chacravarty, A. K., W. Zurkowsky, J. Shine, and B. G. Rolfe. 1982. Symbiotic nitrogen fixation: molecular cloning of Rhizobium genes involved in exopolysaccharide synthesis and effective nodulation. J. Mol. Appl. Genet. 1:585-596.

21. Chen, H., M. Batley, J. M. Redmond, and B. G. Rolfe. 1985. Alteration of the effective nodulation properties of a fastgrowing broad host range Rhizobium due to changes in exopolysaccharide synthesis. J. Plant Physiol. 120:331-349.

22. Clark, M. F., and H. N. Adams. 1977. Characteristics of the microplate method of enzyme-linked immunosorbent assay for the detection of plant viruses. J. Gen. Virol. 34:475-483.

23. Clover, R. H., J. Kieber, and E. R. Signer. 1989. Lipopolysaccharide mutants of Rhizobium meliloti are not defective in symbiosis. J. Bacteriol. 171:3961-3967.

24. Dazzo, F. B., G. L. Truchet, R. I. Hollingsworth, E. M. Hrabak, H. Stuart Pankratz, S. Philip-Hollingsworth, J. L. Salzwedel, K. Chapaman, L. Appenzeller, A. Squartini, D. Gerhold, and G. Orgambide. 1991. Rhizobium lipopolysaccharide modulates infection thread development in white clover root hairs. J. Bacteriol. 173:5371-5384.

25. DeMaagd, R. A., A. S. Rao, I. H. M. Mulders, L. Goosen-de Roo, M. C. M. Van Loosdrecht, C. A. Wijfielman, and B. J. J. Lugtenberg. 1989. Isolation and characterization of mutants of Rhizobium leguminosarum bv. viciae 248 with altered lipopolysaccharides: possible role of surface charge or hydrophobicity in bacterial release from the infection thread. J. Bacteriol. 171:1143-1150.

26. Dénarié, J., and P. Roche. 1992. Rhizobium nodulation signals, p. 295-324. In D. P. S. Verma (ed.), Molecular signals in plant-microbe interactions. CRC Press, Boca Raton, Fla.

27. Dubois, M., K. A. Gilles, J. K. Hamilton, P. A. Rebers, and F. Smith. 1956. Colorimetric method for determination of sugars and related substances. Anal. Chem. 28:350.

28. Fåhraeus, G. 1957. The infection of clover root hairs by nodule bacteria studied by a simple glass slide technique. J. Gen. Microbiol. 16:374-381.

29. Finan, T. M., E. Hartwieg, K. LeMieux, K. Bergman, G. C. Walker, and E. Signer. 1984. General transduction in Rhizobium meliloti. J. Bacteriol. 159:120-124.

30. Galanos, C., and O. Lüderitz. 1975. Electrodialysis of lipopolysaccharide and their conversion to uniform salt forms. Eur. J. Biochem. 54:603-610.

31. Geremía, R. A., S. Cavaignac, A. Zorreguieta, N. Toro, J. Olivares, and R. A. Ugalde. 1987. A Rhizobium meliloti mutant that forms ineffective pseudonodules in alfalfa produces exopolysaccharide but fails to form $\beta-(1 \rightarrow 2)$ glucan. J. Bacteriol. 169:880-884.

32. Goosen-de Roo, L., R. de Maagd, and B. J. J. Lugtenberg. 1991. Antigenic changes in lipopolysaccharide I of Rhizobium leguminosarum bv. viciae in root nodules of Vicia sativa subsp. nigra occur during release from infection threads. J. Bacteriol. 173: 3177-3183.

33. Halverson, J. L., and G. Stacey. 1986. Signal exchange in plant-microbe interactions. Microbiol. Rev. 50:193-225.

34. Jensen, H. L. 1942. Nitrogen fixation in leguminous plants. I. General characters of root nodule bacteria isolated from species of Medicago and Trifolium in Australia. Proc. Linn. Soc.
N. S. W. 66:98-108.

35. Kamberger, W. 1979. Ouchterlony double diffusion study on the interaction between legume lectins and rhizobial cell surface antigens. Arch. Microbiol. 121:83-90.

36. Kannenberg, E. L., S. S. Sindhu, and N. J. Brewin. 1988. Correlation between Rhizobium lipopolysaccharide structure and the ability to grow under calcium stress, p. 476. In $\mathrm{H}$. Bothe, F. J. de Brujin, and W. E. Newton (ed), Nitrogen fixation: hundred years after. Gustav Fischer, Stuttgart, Germany.

37. Karkhanis, Y. D., J. Y. Zeltner, J. J. Jackson, and D. J. Carlo. 1978. A new and improved microassay to determine 2-keto-3deoxyoctonate in lipopolysaccharide of gram-negative bacteria. Anal. Biochem. 85:595-601.

38. Kato, G., M. Murayama, and M. Nakamura. 1979. Role of lectins and lipopolysaccharides in the recognition process of specific legume-Rhizobium symbiosis. Agric. Biol. Chem. 43: 1085-1092.

39. Kropinsky, A. M., D. Berry, and E. P. Greenberg. 1986. The basis of silver staining of bacterial lipopolysaccharides in polyacrylamide gels. Curr. Microbiol. 13:29-31.

40. Laemmli, U. K. 1970. Cleavage of structural proteins during the assembly of the head of bacteriophage T4. Nature (London) 227:680-685.

41. Lagares, A., and G. Favelukes. 1990. Rhizobium meliloti saccharide moiety involved in early symbiotic recognition by alfalfa, $p$. 265. In P. M. Gresshoff, L. Evans Roth, G. Stacey, and W. E. Newton (ed.), Nitrogen fixation: achievements and objectives. Chapman and Hall, New York.

42. Leigh, J. A., E. R. Signer, and G. C. Walker. 1985. Exopolysaccharide deficient mutants that form ineffective nodules. Proc. Natl. Acad. Sci. USA 82:6231-6235.

43. Long, S. R. 1989. Rhizobium-legume nodulation: life together in the underground. Cell 56:203-214.

44. Long, S. R. 1989. Rhizobium genetics. Annu. Rev. Genet. 23:483-506.

45. Müller, P., M. Hynes, D. Kapp, K. Niehaus, and A. Pühler. 1988. Two classes of Rhizobium meliloti infection mutant differ in exopolysaccharide production and in coinoculation properties with nodulation mutants. Mol. Gen. Genet. 211:17-26.

46. Noel, K. D., K. A. Vandenbosch, and B. Kulpaca. 1986. Mutations in Rhizobium phaseoli that lead to arrested development of infection threads. J. Bacteriol. 168:1392-1401.

47. Priefer, U. B. 1989. Genes involved in lipopolysaccharide production and symbiosis are clustered on the chromosome of Rhizobium leguminosarum biovar viciae VF39. J. Bacteriol. 171:6161-6168.

48. Putnoky, P., G. Petrovics, A. Kereszt, E. Grosskopf, D. T. C. Ha, Z. Bánfalvi, and A. Kondorosi. 1990. Rhizobium meliloti lipopolysaccharide and exopolysaccharide can have the same function in the plant-bacterium interaction. J. Bacteriol. 172: $5450-5458$.

49. Rolfe, B. G., and P. M. Gresshof. 1988. Genetic analysis of legume nodule initiation. Annu. Rev. Plant Physiol. Plant Mol. Biol. 39:297-319.

50. Russa, R., T. Urbanik, E. Kowalczuk, and Z. Lorkiewicz. 1982. Correlation between the occurrence of plasmid pUCS202 and lipopolysaccharide alterations in Rhizobium. FEMS Microbiol. Lett. 13:161-165.

51. Russa, R., T. Urbanik, W. Zurkowski, and Z. Lorkiewicz. 1981. Neutral sugars in lipopolysaccharides of Rhizobium trifolii and its non-nodulating mutant. Plant Soil 161:81-85.

52. Sanderson, K. E., T. MacAlister, and J. W. Costerton. 1974. Lipopolysaccharide-deficient (rough) mutants of Salmonella typhimurium to antibiotics, lysozyme and other agents. Can. J. Microbiol. 20:1135-1145.

53. Simon, R., U. Priefer, and A. Pühler. 1983. A broad host range mobilization system for in vivo engineering: transposon mutagenesis in gram negative bacteria. Bio/Technology 1:784-791.

54. Sindhu, S. S., N. J. Brewin, and E. L. Kannenberg. 1990. Immunochemical analysis of lipopolysaccharides from freeliving and endosymbiotic forms of Rhizobium leguminosarum. J. Bacteriol. 172:1804-1813. 
55. Somasegaran, P., and H. J. Hoben. 1985. Methods in legumeRhizobium technology, p. 77-79. NifTAL-MIRCEN.

56. Stacey, G., J.-S. So, L. Evans Roth, S. K. Bhagya Lakashmi, and R. W. Carlson. 1991. A lipopolysaccharide mutant of Bradyrhizobium japonicum that uncouples plant from bacterial differentiation. Mol. Plant-Microbe Interact. 4:332-340.

57. Strum, S., P. Fortnagel, and K. N. Timmis. 1984. Immunoblotting procedure for the analysis of electrophoretically-fractionated bacterial lipopolysaccharide. Arch. Microbiol. 140:198201.

58. Tao, H., N. J. Brewin, and K. D. Noel. 1990. Rhizobium leguminosarum CFN42 lipopolysaccharide antigenic changes induced by environmental conditions. J. Bacteriol. 174:22222229.

59. Tsai, C. M., and C. E. Frasch. 1982. A sensitive silver stain for detecting lipopolysaccharides in polyacrylamide gels. Anal.
Biochem. 119:115-119.

60. Vincent, J. M. 1979. A manual for the practical study of root nodule bacteria. Handbook no. 15 C. IBP, Oxford.

61. Westphal, O., and K. Jann. 1965. Bacterial lipopolysaccharide. Methods Carbohydr. Chem. 5:83-91.

62. Williams, M. N. V., R. I. Hollingsworth, P. M. Brzoska, and E. R. Signer. 1990. Rhizobium meliloti chromosomal loci required for suppression of exopolysaccharide mutations by lipopolysaccharide. J. Bacteriol. 172:6596-6598.

63. Williams, M. N. V., R. I. Hollingsworth, S. Klein, and E. Signer. 1990. The symbiotic defect of Rhizobium meliloti exopolysaccharide mutants is suppressed by $l p s Z^{+}$, a gene involved in lipopolysaccharide biosynthesis. J. Bacteriol. 172:2622-2632.

64. Williamson, P., K. Mattocks, and R. A. Schlegel. 1983. Merocyanine 540, a fluorescent probe sensitive to lipid packing. Biochim. Biophys. Acta 732:387-393. 